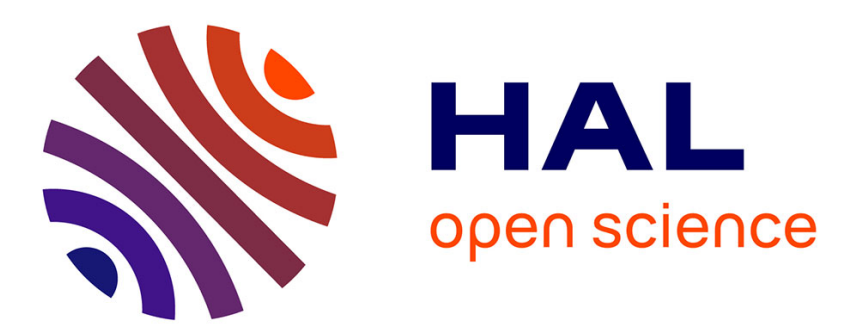

\title{
Simulating Impact of Smart Product-Service Systems
}

Christian Zinke-Wehlmann, Sebastian Frericks, Andreas Kluge

\section{To cite this version:}

Christian Zinke-Wehlmann, Sebastian Frericks, Andreas Kluge. Simulating Impact of Smart ProductService Systems. 22nd Working Conference on Virtual Enterprises (PRO-VE 2021), Nov 2021, SaintEtienne, France. pp.289-300, 10.1007/978-3-030-85969-5_26. emse-03339287

\section{HAL Id: emse-03339287 https://hal-emse.ccsd.cnrs.fr/emse-03339287}

Submitted on 24 Nov 2021

HAL is a multi-disciplinary open access archive for the deposit and dissemination of scientific research documents, whether they are published or not. The documents may come from teaching and research institutions in France or abroad, or from public or private research centers.
L'archive ouverte pluridisciplinaire HAL, est destinée au dépôt et à la diffusion de documents scientifiques de niveau recherche, publiés ou non, émanant des établissements d'enseignement et de recherche français ou étrangers, des laboratoires publics ou privés. 


\title{
Simulating Impact of Smart Product-Service Systems
}

\author{
Christian Zinke-Wehlmann ${ }^{1}$, Sebastian Frericks ${ }^{2}$, and Andreas Kluge ${ }^{2}$ \\ ${ }^{1}$ InfAI e.V., Group Service- and Knowledge Management, \\ Goerdelerring 9, 04109 Leipzig, Germany \\ ${ }^{2}$ Leipzig University, University Computer Centre, Group Research and Development, \\ Augustusplatz 10, 04109 Leipzig, Germany
}

\begin{abstract}
Waves of digitalization and Industry 4.0 currently boost research and development activities for smart product-service systems. The usage of information technology within products (e.g., IoT) and services as well as processing big data leads to the development of novel product-service bundles like functional sales. One of the main barriers of smart PSS innovation is missing information on possible economic (cost/revenue) and ecological (environmental) impacts. This paper presents a novel simulation approach to overcome the named barrier. Methodologically, the paper is based on design science research to develop an appropriate approach. Our simulation model will be able to enhance transparency about the different forms and power of impact of smart PSS. Furthermore, the core of the new approach is the possible low threshold integration of existing data on business model and process model layers into the simulation. Finally, an existing use case demonstrates how the approach can be applied.
\end{abstract}

Keywords: Smart Product-Service System, Simulation, Business Model Innovation

\section{Introduction}

The number of product-service systems (PSS) in various sectors of the economy is rising. The trend of 'servitization' is supported by using smart technology to recognize and address customer needs and create new smart PSS [1]. Thus, the rapid development of technology (e.g., Internet of Things - IoT) and the steadily increasing ability to process big data lead to this 'smartification' of PSS [2]. The technological developments towards smart PSS enhance stakeholders' digital integration and facilitate highly customized product-service bundles for customers - driven by their needs.

Besides customization, there is also a growing demand for sustainable, eco-friendly, and ethically tenable solutions [3]. Novel approaches of transparency and business model innovations are needed to cover these societal and individual customer demands. The potentials of sustainable business models driven by PSS, e.g., through functional sales, have already been discussed in the respective research, e.g., [4]. Using the new wave of 'smartification' [2], driven by digitalization, Industry 4.0, and IoT, PSS business models, have reached the next evolution stage. However, the switch from classical product selling business models to 'smart' and service-oriented models, like functional 
sales, is non-trivial and complex. To evaluate and recreate a business model in a sustainable way, the whole product lifecycle must be considered. Further, novel services must be designed, developed, and maintained. Moreover, rapidly changing technologies (e.g., IoT, web technologies) have to be included in the product and service life cycle. In addition, many competencies must be combined within the innovation and business development process. Thus, the business development of smart PSS is complex, risky with mostly unknown components and costs. As [5] stated out "Costs of PSS can be high when compared to the production of only one product, which includes labor and transaction costs, since a PSS is usually delivered by a group of companies, resulting in hiring and more complicated revenue-sharing scheme" [5]. Therefore, the major obstacle within this innovation process in collaborative networks is the difficulty of estimating the possible future impact of the novel business model - the economic impact for both customers and the businesses and the ecological impact. There is a significant gap in supporting PSS development processes, e.g., business model development, by easily simulating possible PSS scenarios based on business model information (e.g., key resources, revenue structure) and target process descriptions (e.g., key processes and activities) to calculate its possible impacts. However, simulation of PSS solutions is not a novel approach. One highly relevant but still missing detail of the currently used simulations is simple compatibility with existing business development processes (e.g., business model canvas, process management standards) in the companies and a low usage threshold. A novel smart PSS simulation approach is needed to customize and configure smart PSS and predict potential benefits and risks to overcome this gap. Thus, we want to approach the main research questions: How can a simulation approach support smart PSS business innovation processes? How to combine basic information of the target business model and business processes to enable a simulation and predict possible revenues, costs, and environmental KPIs?

\section{Methodology}

The method chosen in the present case is based on the design science research approach (DSR) described by [6] and [7]. These are I: Identify and describe the problem, II: Develop objectives for a solution, III: Design and develop artifact, VI: Demonstrate and V: Evaluate, as well as VI: Communicate. The process described is continuous and multi-stage. The paper presents the results of our research's first steps, given by a realworld scenario of our industrial partners. The scenario will be introduced in Section 4. We are currently working within stage III to design and implement a simulation environment. While the work is still in progress, the results enrich the current state of the art of simulation approaches for smart and collaborative PSS development. Although design science research's strength lies in its practicality, various DSR models simultaneously propose elaborating a clear state of the art of the given problem to ensure scientific rigor $[6,8]$. Therefore, in the present paper, a thorough state of the art is presented first. 


\section{Simulation of Smart Product-Service Systems - the State of the} Art

First, the term of smart product-service systems (smart PSS) will be introduced. The combination of tangible products and intangible services is referred to in the literature as product-service systems [9]. Smart PSS are combining products, services, and ICT services into smart packages and customizable solutions [10]. With the rise of sensors and IoT, mobile devices and other products start to collect data, IT services process them to information, and platform services bring them into use for customers or providers. While the benefits of smart PSS for customer and provider are the reduction of costs, the reduction of environmental impact, as well as efficient use of the equipment, one of the significant risks is the difficulty in measuring results as well as the question of revenue streams and success conditions [5]. Thus, the paper will develop a simulation model to overcome these challenges. The next part will briefly introduce the current simulation approaches within the (smart) PSS domain.

Simulation is a very broad concept, with and without information technology, to replicate real-world processes and situations for various purposes [11]. This paper only refers to IT-based (computer-based) simulation approaches, esp. for Industry 4.0, smart manufacturing, and PSS. A lot of work has been done within the domain of process and (IT) service simulation, e.g., for the model-driven service engineering approach [12] or smart manufacturing orchestration approaches [13]. These approaches are fruitful for business process design, e.g., optimize time and costs of (IT) services and sustainable KPIs [14], but hard to use for ICT-based product-service systems. Further, Jaghbeer et al. [15] conclude "that current tools and methods extensively focus on manufacturing, especially sustainable manufacturing, while less attention is given towards other life cycle phases" [15]. The challenges which came with other life cycle phases are demonstrated by Goodall et al., who create a simulation model for data-driven re-manufacturing service [16] in Industry 4.0 environments. They demonstrate how end-of-life services (also given for PSS) can be integrated into planning and manufacturing processes. In addition, Angelopoulou et al. simulate the human factor to predict the human error probability in Industry 4.0 [17]. With Industry 4.0, manufacturing processes and IT services are getting highly digitalized, and this opens space for simulation approaches to optimize its impact (economically and ecologically). Further, Rondini et al. give a brief overview about the PSS simulation approaches [18] and summarize "that some attempts to evaluate the performance perceived by the customers, the company efficiency and the PSS environmental performance through BPS [Business Process Simulation] already exist, and that simulation techniques can potentially help to gather the dynamics of a PSS provision process." [18]. This analysis shows different simulation approaches (discrete, agent-based, system dynamics) that can be used or combined for different focusses in PSS development: Focusing on customer (behavior and interaction), on efficiency and resources as well as on environmental impact. While the combination of all methods is recommendable, this paper concentrates on the 'smartification' of PSS business model innovation towards smart and collaborative systems, exemplary on simulation of 'smart' functional sales to predict economic and ecological impact (e.g., compared to classical product sales and service delivery). 


\section{Results - Supporting PSS Development by a Simulation Approach}

One of the most prominent business cases for PSS business models is functional sales, where the functions are sold. A simplified use case from our industrial partners is the development of "drilling services", where no tangible product (professional drillers) is sold to the customer (product-oriented PSS with additional service), but the function "drilling" is sold (smart PSS) - see Business Model comparison as part of the economical layer following Joyce and Paquin [19] in table $1^{1}$. To develop these services from the existing manufacturing model, the driller producer needs to 'smartifice' and 'servitize' its products by including novel technologies, integrating them on a digital platform, and building new business processes/partnerships for maintenance, repair, and re-manufacturing. Besides these developments of value proposition and value creation processes, the producer needs to define the value capturing model - revenue and cost structure.

Table 1 Product-Oriented vs. Smart PSS on Drilling Example

\begin{tabular}{|c|c|c|}
\hline $\begin{array}{l}\text { Drilling } \\
\text { Example }\end{array}$ & $\begin{array}{l}\text { Product-Oriented } \\
\text { PSS }\end{array}$ & Smart Product-Service System \\
\hline \multirow{2}{*}{$\begin{array}{l}\text { Revenue } \\
\text { (Value } \\
\text { Capturing) }\end{array}$} & One-time payment & Pay-per-drill \\
\hline & $\begin{array}{l}\text { Number of } \\
\text { sold drillers }\end{array}$ & Number of drills \\
\hline $\begin{array}{l}\text { (Key) } \\
\text { Resources }\end{array}$ & Materials and Store & $\begin{array}{l}\text { Smart Driller (with IoT) and a platform } \\
\text { (drilling activities, contract details, state of } \\
\text { the machine, etc.) }\end{array}$ \\
\hline $\begin{array}{l}\text { Value } \\
\text { Propositions } \\
\text { (Product) }\end{array}$ & $\begin{array}{l}\text { Driller, } \\
\text { Maintenance }\end{array}$ & Drilling \\
\hline $\begin{array}{l}\text { (Key) } \\
\text { Activities }\end{array}$ & $\begin{array}{l}\text { Manufacturing } \\
\text { (Supply Chain) and } \\
\text { Selling }\end{array}$ & $\begin{array}{l}\text { Customer Services (e.g., maintenance, plat- } \\
\text { form services), manufacturing and re-manu- } \\
\text { facturing (supply chain) }\end{array}$ \\
\hline Costs & $\begin{array}{l}\text { Materials, Manufac- } \\
\text { turing, Marketing }\end{array}$ & $\begin{array}{l}\text { (re-)Manufacturing, Customer Services, } \\
\text { Service platform (IT-Services), Marketing }\end{array}$ \\
\hline
\end{tabular}

The switch from product and service selling to 'smart' functional sales as described is complex, and besides the challenges of customer acceptance, decision-makers must estimate possible impacts. While on product-oriented PSS, product and services are loosely coupled, for example, in its revenue and cost structure, in smart PSS, the product/function are closely tied. Therefore, the revenue of smart PSS depends on welldesigned services and resources. This paper aims to develop a simulation model for such smart product-service Systems to support decision-makers on business model innovations towards smart PSS.

${ }^{1}$ Customer Relationship, Segments and Channels have not been mentioned, because it is not focus of the used simulation approach - we will argue later on why. Further we concentrate on economical layer, and will give a brief introduction later on the other layer. 
A starting point for the simulation was deciding what kind of simulation is suitable for the given problem. We choose a process-based discrete event simulation (DES) approach because:

- Services (smart drilling service) are realized when the respective functions are used (drilling),

- $\quad$ Functions are measurable and discrete variables (count of drilling),

- Services are processes where resources (driller, platform, and customer) get integrated (in a range of time) and

- $\quad$ Resources (driller) have functions (drilling) and other measurable performance indexes (costs per time, C02-footprint, energy costs).

Other approaches, like agent-based approaches, may also be successful adapted for our purpose, but more likely for cooperation [20] and customer acceptance [21]. While integrating these approaches has been shown in [18], we concentrate on a novel generic way to simulate smart PSS from the provider's business model innovation perspective. Further, DES is mainly based on three concepts: the events, the objects' activities, and the process. While an event triggers the object's activities through changing object states, the object's activities are defined as a time interval mostly between two object states, and the processes refer to the sum of activities and states for an object or the simulation [22]. The concept that processes a set of activities is quite similar to process models (like BPMN), the problem is that, for example, BPMN is not suitable for real automated transformation in simulation models, like [23] stated out, "that there are quite a few ambiguous elements, missing concepts, and redundant elements in BPMN" [23]. This is one of the major gaps in the modeling and interconnection of objects and resources [24] within process models. Our approach uses existing terms from business models (resources, processes) and business processes (activities, gates, lanes) to integrate the information into our simulation and predict business model impact (revenue and cost structure as well as ecological impact [19]). An overview is given in Figure 1 au-dessous.

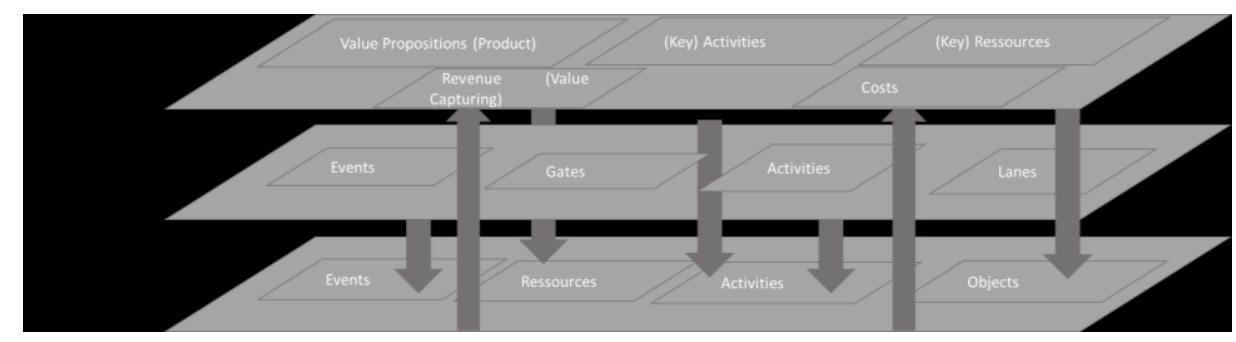

Figure 1: Integration from Business Model and Business Process to Simulation

The transmission of information from the business model canvas over business processes to simulation and back implies (practical) difficulties because each level includes different granularities of information. To overcome these difficulties, we suggest the following steps: (1) Define the (key) resources, processes, and activities for the business model (e.g., through business model canvas); (2) Define the selling functions and bring them into relation with the (key) resources; (3) Develop process models for key 
processes. Define customer, supplier, and company activities and processes in a standardized way, e.g., described with the help of BPMN (4) Define cost, revenue, and environmental (or other) indexes for function, activities, and sub-processes.

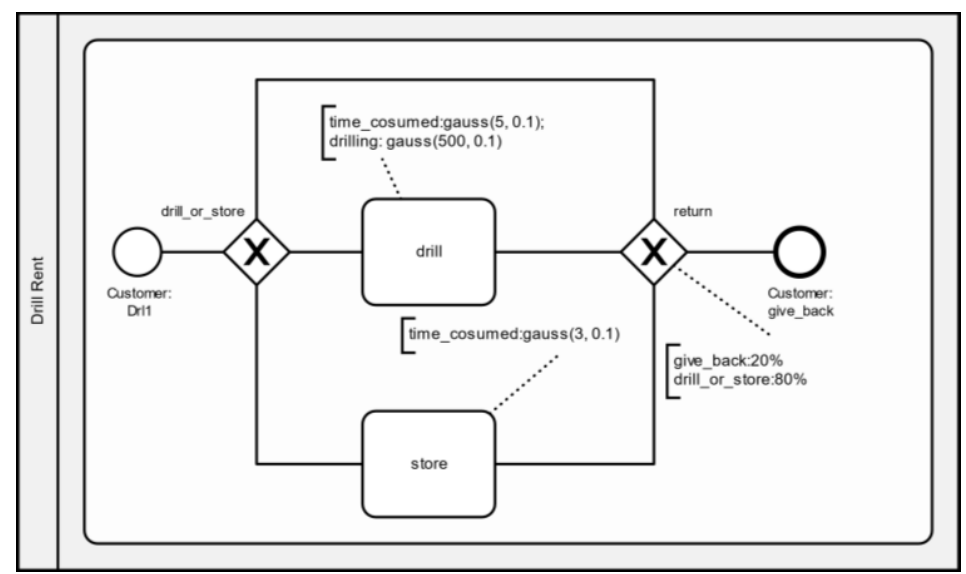

Figure 2: Key Drilling Process

The definitions of step 1 can be found au-dessus in Table 1. In step 2, we define the value proposition "drilling", which is linked to key-resource driller (remember it is an oversimplified case). For step 3, we developed a process model for our simulation approach. The smartified subprocess as a simplified BPMN is shown in Figure 2. We also include the cost structure as comments to demonstrate step 4. There is a fixed cost for keeping the drill and a dynamic cost for using the drill in this scenario. To bridge all the information and bring them into a simulation approach, we do follow:

- Extract resources and functions from Business Modell (Driller, drilling)

- Extract the process elements from the BPMN and classify and associate them with the used resource (drill) and a resource-specific activity (drilling) for cost calculation and its descendants.

- $\quad$ Build a JSON structure to process.

- Finally, the JSON model is fitted to a generic simulation model based on Simply.

Thus, resources will be initialized as well as gates and activities. The start function is decided based on the first function following the process source and is either a gate or an activity. The current generic model is limited to exclusive gates, which are only moving the process state, based on statistical distribution, to the next activity and activities which calculate the costs or any other KPI and time of the process.

We demonstrate how to combine data for smart PSS development with this prelimited model and process, like functional sales. The simulation enables a flexible PSS business development by estimating the cost, revenue, generic KPIs, and environmental impact of given value propositions, key resources, and key activities/processes. Thus, better decisions, flexible pricing models, as well as bonus program options can be made. Information about economic and ecological impacts may also trigger re-design and robustness of products, novel development of end-of-life services, and other activities to 
enhance efficiency of the provided PSS, in terms of functional sales. Finally, the digital simulation (as an online service) enables cross-organizational development of business model innovation by combining different developers' and departments' information. Thus, decision-makers obtain a more valid basis for sustainable business innovations.

\section{Discussion and Conclusion}

The evolution of smart PSS is one way to a more sustainable economy both economical and ecologically. Walking over the edge to new business models without intense consideration of risks and chances takes companies into jeopardy. The approach proposed in this paper enriches the arsenal of a suitable methodology for smart business model innovation by a new integrated simulation model. Our approach gives the opportunity to test hypothetical business models' ideas within a sandbox environment as a digital twin. It contributes to the field of smart PSS simulation mainly by giving the possibility to transform common business model notations into a for simulation usable format without enormous effort.

The required data is generated from existing business model layers as well as business process layers. The threshold of supplying the simulation with the named data is low, as the data is usually already stored in the company. Looking forward, the model will be developed further to find a way to not only test hypothetical models but evaluate business models and give input in smart innovation processes on product-service systems. However, there are still a lot of limitations. First, the model and the simulation tool are still under development. The first real PSS innovation simulations and first real proof of usability are planned within the next year. Second, the model still concentrates on specific aspects of the sustainable Business Model Innovation Canvas [19]. There will be a high demand to include agent-based simulation approaches to integrate the customer-side and the social and supply dimension of business development, which we need to consider.

\section{References}

1. Zheng P, Wang Z, Chen C-H et al. (2019) A survey of smart product-service systems: Key aspects, challenges and future perspectives. Advanced Engineering Informatics 42:100973. https://doi.org/10.1016/j.aei.2019.100973

2. Schuh G, Zeller V, Hicking J et al. (2019) Introducing a methodology for smartification of products in manufacturing industry. Procedia CIRP 81:228-233. https://doi.org/10.1016/j.procir.2019.03.040

3. Scholz U, Pastoors S, Becker JH et al. (2018) Praxishandbuch Nachhaltige Produktentwicklung. Springer Berlin Heidelberg, Berlin, Heidelberg

4. van Halen MSc CJG, te Riele MSc, Harry RM (1999) Product Service systems, Ecological and Economic Basics

5. Moro S, Cauchick-Migue PA, Mendes GHdS (2020) Product-service systems benefits and barriers: an overview of literature review papers. Int $J$ Ind Eng Manag 11:61-70. https://doi.org/10.24867/IJIEM-2020-1-253 
6. Peffers K, Tuunanen T, Rothenberger MA et al. (2007) A Design Science Research Methodology for Information Systems Research. Journal of Management Information Systems 24:45-77. https://doi.org/10.2753/MIS0742-1222240302

7. Hevner A, Chatterjee S (2010) Design Research in Information Systems, vol 22. Springer US, Boston, MA

8. Hevner AR (2007) A three cycle view of design science research. Scandinavian journal of information systems 19:4

9. Baines TS, Lightfoot HW, Evans S et al. (2007) State-of-the-art in product-service systems. Proceedings of the Institution of Mechanical Engineers, Part B: Journal of Engineering Manufacture 221:1543-1552. https://doi.org/10.1243/09544054JEM858

10.Valencia A, Mugge R, Schoormans J et al. (2015) The design of smart product-service systems (PSSs): An exploration of design characteristics. International Journal of Design 9

11.Simões-Marques MJ (2015) Modeling and Simulation in System Life Cycle. Procedia Manufacturing 3:785-792. https://doi.org/10.1016/j.promfg.2015.07.331

12.Boyé H, Ducq Y, Zacharewicz G et al. (2016) SLMToolBox: enterprise service process modelling and simulation by coupling DEVS and services workflow. IJSPM 11:453. https://doi.org/10.1504/IJSPM.2016.10001547

13.Gorecki S, Possik J, Zacharewicz G et al. (2020) A Multicomponent Distributed Framework for Smart Production System Modeling and Simulation. Sustainability 12:6969. https://doi.org/10.3390/su12176969

14.Rocca R, Rosa P, Sassanelli C et al. (2020) Integrating Virtual Reality and Digital Twin in Circular Economy Practices: A Laboratory Application Case. Sustainability 12:2286. https://doi.org/10.3390/su12062286

15.Jaghbeer Y, Hallstedt SI, Larsson T et al. (2017) Exploration of Simulation-Driven Support Tools for Sustainable Product Development. Procedia CIRP 64:271-276. https://doi.org/10.1016/j.procir.2017.03.069

16.Goodall P, Sharpe R, West A (2019) A data-driven simulation to support re-manufacturing operations. Computers in Industry 105:48-60. https://doi.org/10.1016/j.compind.2018.11.001

17.Angelopoulou A, Mykoniatis K, Boyapati NR (2020) Industry 4.0: The use of simulation for human reliability assessment. Procedia Manufacturing 42:296-301. https://doi.org/10.1016/j.promfg.2020.02.094

18.Rondini A, Tornese F, Gnoni MG et al. (2017) Hybrid simulation modelling as a supporting tool for sustainable product service systems: a critical analysis. International Journal of Production Research 55:6932-6945. https://doi.org/10.1080/00207543.2017.1330569

19.Joyce A, Paquin RL (2016) The triple layered business model canvas: A tool to design more sustainable business models. Journal of Cleaner Production 135:1474-1486. https://doi.org/10.1016/j.jclepro.2016.06.067

20.Campos P, Brazdil P, Mota I (2013) Comparing Strategies of Collaborative Networks for R\&D: An Agent-Based Study. Comput Econ 42:1-22. https://doi.org/10.1007/s10614-0139376-9

21.Lieder M, Asif FMA, Rashid A (2017) Towards Circular Economy implementation: an agentbased simulation approach for business model changes. Auton Agent Multi-Agent Syst 31:1377-1402. https://doi.org/10.1007/s10458-017-9365-9

22.Lara J de, Guerra E, Boronat A et al. (2014) Domain-specific discrete event modelling and simulation using graph transformation. Softw Syst Model 13:209-238. https://doi.org/10.1007/s10270-012-0242-3

23.Guizzardi G, Wagner G (2011) Can BPMN Be Used for Making Simulation Models? In: Barjis J, Eldabi T, Gupta A (eds) Enterprise and Organizational Modeling and Simulation, vol 88. Springer Berlin Heidelberg, Berlin, Heidelberg, pp 100-115

24.Enstone LJ, Clark MF (2006) BPMN and Simulation. Lanner Group Limited 